\title{
A Conceptual Model of Service Exchange in Service- Dominant Logic
}

\author{
Geert Poels \\ Faculty of Economics and Business Administration, Ghent University, Tweekerkenstraat 2, \\ 9000 Gent, Belgium \\ Geert.Poels@UGent.be
}

\begin{abstract}
The service system is the basic abstraction of Service Science. This paper proposes the Resource-Service-System model as a conceptual model of service systems interacting in service exchanges, assuming a service-dominant logic economic worldview. The paper explains how the model was developed starting from the Resource-Event-Agent business model ontology, taking into account insights gained from studying Service Science literature and existing service ontologies. The paper also explains how different model views can contribute to study various aspects of service systems and exchanges.
\end{abstract}

\section{Introduction}

Service Science is the study of the application of the resources of one system for the benefit of another system in the context of an economic exchange [1]. The systems referred to in this definition are service systems [2]. In [1] the service system concept has been formally defined in terms of general systems theory, assuming a view on economic activities that can be described as Service-Dominant Logic (SDL) [3]. In SDL each economic exchange between natural or legal persons is viewed as an exchange of service for service, where service is considered as the process of doing something for another party. This stands in contrast with the dominant economic worldview, Goods-Dominant Logic (GDL) [3], in which goods (tangible production outputs embedded with value) are the focus of economic exchanges and services are merely seen as an intangible type of output or an add-on that enhances the value of goods [4].

A recent symposium on Service Science emphasized the need for modelling and simulation tools to help studying service systems [5]. Current challenges for Service Science include the formal representation and measurement of work in service systems [2] and the development of a shared vocabulary (i.e. an ontology) to describe service systems [1]. This paper aims to contribute to Service Science by proposing a conceptual model of service exchange in SDL. The model is intended as an instrument to be used in the study of service systems and their interaction in the context of service exchanges. The model is not portrayed as an ontology for service or service systems as in its present form it does not satisfy criteria like being completely and explicitly specified and being formally represented. As it stands, the model is a conceptualization that might provide a basis for further ontology development. 
Business modelling plays an important role in Service Science [6]. Although many sorts of things can be viewed as service systems, including persons, families, cities and government agencies [1], enterprises constitute a major category of service systems when service exchanges are considered in an economic context (as is done in SDL). A business model expresses the business logic of an enterprise in terms of objects and relationships that allow "a simplified description and representation of what value is provided to customers, how this is done and with which financial consequences" [7]. Modelling enterprises as service systems, emphasizing the application of their resources for the benefit of other systems in the context of economic exchange, is therefore a business modelling effort.

Business modelling knowledge has been specified and formalized in business model ontologies, which offer concepts in terms of which business models can be articulated. According to [8], the most comprehensive and well defined ontologies for business models are the Resource-Event-Agent (REA) ontology [9], the $\mathrm{e}^{3}$-value ontology [10], and the Business Model Ontology (BMO) [11]. BMO takes the perspective of a single enterprise facing its environment without focusing on the actual economic exchanges between the enterprise and actors in its environment. REA and $\mathrm{e}^{3}-$ value are different as they emphasize the creation of value through economic exchanges. $\mathrm{E}^{3}$-value contains concepts to describe networks of actors exchanging value objects (i.e. things of value) as well as value activities, meaning activities performed by these actors to create the value objects. REA is centred on constellations of resources, events, and agents that are mirrored through the principle of economic reciprocity. It contains concepts to describe what things of value (e.g. goods) an enterprise gives up in exchange for other things of value (e.g. money) it takes in, clearly identifying which parties are involved in these exchanges.

Service systems are configurations of resources [1] and being able to represent the resource composition of service systems and the resources applied in services is an important requirement for the conceptual model of service exchange. Whereas mirrored Resource/Event/Agent constellations can also account for internal conversion processes (i.e. converting raw materials into finished goods) [12], the production of value objects cannot be described in detail using $\mathrm{e}^{3}$-value as value activity is a 'black box' concept. $\mathrm{E}^{3}$-value puts resources in the picture only if they flow between value activities or actors. REA is able to identify all resources needed to produce value. Therefore, REA was chosen for providing a foundation for the conceptual model of service exchange.

The rest of this paper is structured as follows: section 2 contains background material and discusses related work. Section 3 presents in an incremental manner the proposed conceptual model of service exchange in SDL. Section 4 concludes the paper.

\section{Background and Related Work}

\subsection{Service-Dominant Logic and Service Systems}

Service in SDL is defined as the application of specialized competences (knowledge and skills) for the benefit of another entity [13]. SDL replaces the traditional classifi- 
cation of products as either goods or services ${ }^{1}$ by the distinction between operand and operant resources. Operand resources are passive resources that require action to make them valuable, whereas operant resources are active resources that are capable of creating value. Competences are embodied in operant resources and the acting of operant resources upon other resources is what constitutes service. For instance, a car mechanic is an operant resource that embodies car repair/servicing knowledge and skills and that uses operand resources like garage tools, facilities (e.g. a garage pit) and consumables (e.g. motor oil) to repair or service a car, which is another operand resource.

It is important to notice that goods do not disappear in SDL as they are conveyors of competences [4], e.g. it is via the garage tools, facilities, etc., that the car repair/servicing competence is applied to the car. Further, it is clear that service is a collaborative value creation process in which there is neither value producer nor value consumer, but each party co-creates value by bringing in or making accessible its unique resources [4]. In the example, the car owner needs to make his car accessible for repair or servicing, otherwise no service is possible and no value is created. SDL stresses this resource integrator role of the service beneficiary [15]. An entity benefits from a service by integrating the competences applied by another entity into its own resources.

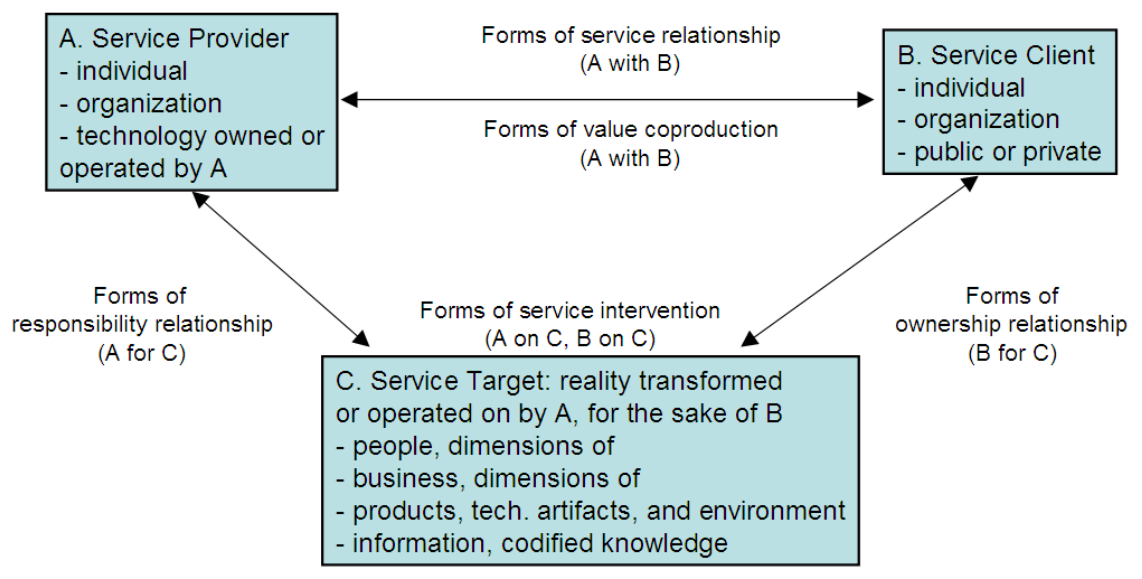

Fig. 1. Definition of service in terms of relationships and actions among service provider, service client, and service target [2]

The entities involved in a service are service systems, meaning "valuecoproduction configurations of people, technology, other internal and external service systems, and shared information (such as language, processes, metrics, prices, policies, and laws)" [16]. Service systems interact in the role of service provider or service client. Fig. 1 shows a service system A (the service provider) taking responsibil-

${ }^{1}$ Traditionally, services are viewed as second-class products that suffer from 'shortcomings' like intangibility (inability to perceive by the senses), heterogeneity (inability to standardize), inseparability (of production and consumption) and perishability (inability to store) [13], [14]. 
ity for transforming or operating on a service target $\mathrm{C}$ that is owned by service system $\mathrm{B}$ (the service client). The model shows that the intervention of both service systems $\mathrm{A}$ and $\mathrm{B}$ is required to create value for the service beneficiary (i.e. the service client).

Recently, Maglio et al. [1] defined the service system concept in terms of SDL. In this view, service systems are configurations of resources ${ }^{2}$, of which at least one operant resource, that interact to co-create value. In our example, both the garage and the car owner are service systems. The garage applies operant and operand resources (e.g. the competence embodied in the car mechanic, a garage pit, tools, etc.) and the car owner integrates these applied resources with the car (i.e. an operand resource controlled by the car owner) by making the car accessible for servicing.

The shift from GDL to SDL represents a shift in the logic of economic exchange rather than a shift in the type of product under investigation [4]. In SDL, service is exchanged for service on the basis of voluntary, economic reciprocity. Accordingly, Maglio et al. formally define a service system as "an open system (1) capable of improving the state of another system through sharing or applying its resources (i.e., the other system determines and agrees that the interaction has value), and (2) capable of improving its own state by acquiring external resources (i.e., the system itself sees value in its interaction with other systems)" [1]. Hence, service systems do not interact to create value for just one of them. They interact in mutually reciprocal services such that value is created for both of them. The garage applies resources to improve the state of the car owner (i.e. the car owner perceives benefits in having his car repaired or serviced) and the car owner applies resources to improve the state of the garage (i.e. he transfers money from his account to the garage's account). Paying the garage is the reciprocal service for repairing or servicing the car.

Service exchange is the economic motive for service systems to engage in interactions with other service systems. This reality is not represented in Fig. 1. This paper proposes a conceptual model of service systems interacting in services with an explicit representation of service exchange. To explain the basis for this conceptual model, the next sub-section reviews REA. Next, three ontologies are reviewed that describe the nature of service and related concepts.

\subsection{The Resource-Event-Agent Ontology}

REA originates in an accounting data model proposed by William E. McCarthy in 1982 [17]. Fig. 2 shows the core concepts and relations of REA; further ontological extensions and refinements have been proposed [9], [12], [18], [19]. An economic resource is a valuable good, right, or service that is presently under the identifiable control of a particular person. Person, in this context, must be read as a natural or legal person, recognized by law as having legal rights and duties, able to make commitment(s), assume and fulfil resulting obligation(s), and able to be held accountable for its action(s) [20]. An economic resource is under the control of a person if that person owns the resource or is able to derive economic benefit from it [20]. An economic

\footnotetext{
${ }^{2}$ Including physical resources with legal rights (people), conceptual resources with legal rights (organizations), conceptual resources treated as property (shared information) and physical resources treated as property (technology) [1].
} 
event is an occurrence in time that results in an inflow or outflow of economic resources in the context of an economic exchange of economic resources between persons. An economic agent is a person that is responsible for an economic event that occurs in the context of an economic exchange. Two economic agents participate in each economic event: one agent in the role of provider of economic resources and another agent in the role of receiver of economic resources.

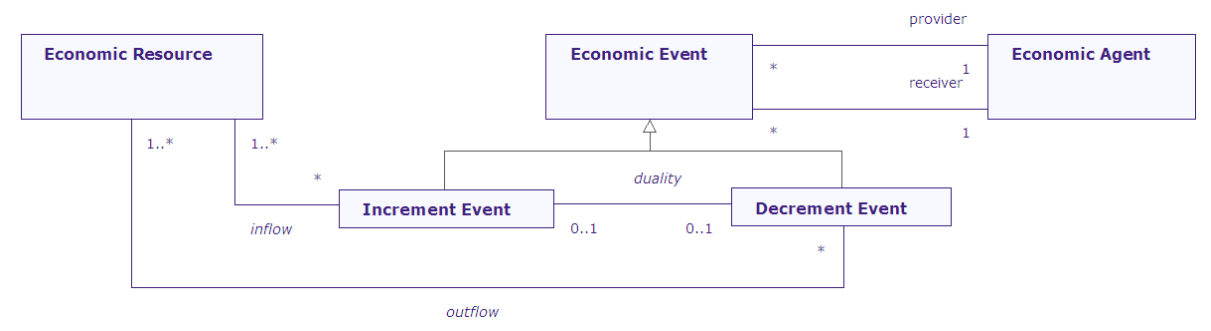

Fig. 2. Basic Resource-Event-Agent Model (based on [19])

REA emphasizes that enterprises create value through economic exchange. Fig. 2 can therefore serve as a conceptual model of economic exchanges of resources between agents. Resources are exchanged through dual economic events, in which each event has two roles: increment event for the receiving agent and decrement event for the providing agent. The duality relation between increment and decrement events has the status of an 'axiom' in REA, signifying that agents will only participate in economic exchanges on the basis of economic reciprocity (i.e. quid pro quo). The loss in value that is caused by giving up resources must be balanced by a gain in value that is caused by getting other resources.

Being rooted in the accounting discipline, REA assumes the traditional GDL worldview and considers services as a type of economic resources. ${ }^{3}$ This means that services can be exchanged for other economic resources. For instance, the garage and the car owner can exchange a car repair service for money. The flow of resources is caused by economic events. So apart from identifying car repair service as an economic resource, it is necessary to identify an economic event that causes the car repair service to flow from the garage to the car owner. This event, e.g. service delivery, is a decrement event for the garage and an increment event for the car owner. In return the car owner pays the garage, causing a flow of money from car owner to garage. Payment is the dual economic event of service delivery.

The view of service as a resource stands in sharp conflict with SDL which considers service as a process. The REA distinction between services (as economic resources) and services delivery (as economic events) is therefore not supported by SDL. According to SDL, resources have no intrinsic value but are valued through their application (in a service) and integration with other resources [13]. This contradicts the REA view of services delivery as a decrement event for the provider (i.e. the provider loses value) and an increment event for the receiver (i.e. the receiver gains

${ }^{3}$ The view of 'service as a resource' implies that at any moment services can be materialized, which is required for valuation of enterprises. 
value). So, although REA offers a conceptual model of economic exchange, in its current form it is invalid as a conceptual model of service exchange in SDL.

\subsection{Service Ontologies}

Weigand et al. [21] propose the Basic Service Ontology, which is based on REA concepts (Fig. 3). A distinction is made between two types of resources: external resources are those that can be exchanged between agents whereas internal resources cannot be exchanged. Consistent with the GDL/REA view, a service is an external resource "as it is viewed as valuable by some agent and can be exchanged between agents" [21]. Unlike REA, the special nature of services is recognized as they are external resources that have as goal to modify and add value to other resources. This is modelled by the hasGoal relation between service and economic event. The economic resources that are modified are identified via the concerns relation.

The realization of a service is distinguished from the service itself. A service can be realized in different ways (modelled as the realizes relation with process) and service realization processes are governed by policies, which are internal resources. To address workflow and service composition aspects in realizing services, the work process concept is introduced.

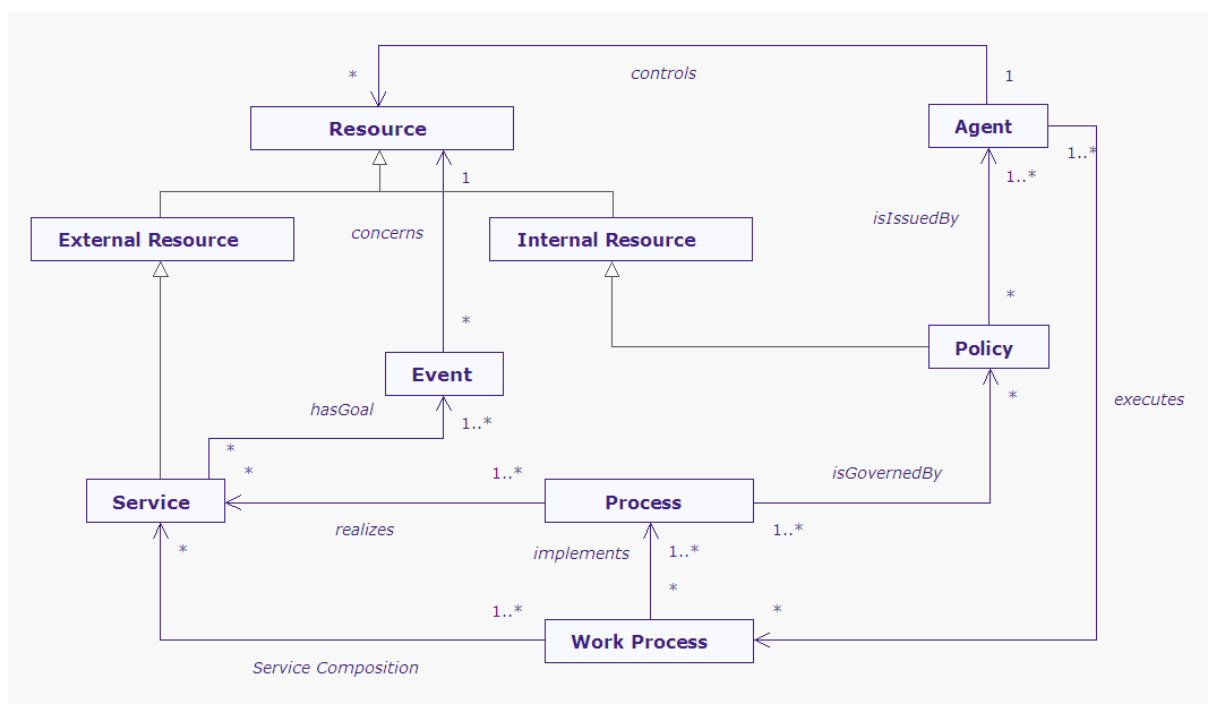

Fig. 3. Basic Service Ontology [21]

Although not shown in Fig. 3, the Basic Service Ontology also recognizes that service exchanges meet the REA duality axiom. The view that services are resources that can be exchanged is however not in line with SDL. Further, the value co-creation that is so essential for the SDL view on service is not addressed very well, as agents control resources and execute work processes but it is nowhere implied that agents should collaborate, each bringing in their own resources [4], to create value. In SDL, service 
is a collaborative process and not something that is produced by one party (i.e. service realization) and then consumed by another party (i.e. achieving the service's goal). The decoupling of production and consumption is typical GDL thinking where it is promoted for efficiency reasons [4].

Other ontologies of service or service system have been proposed or are being developed. In [22], Alter gives a theoretical foundation for the concept of service system using Work System Theory, which is recognized as another normative view on describing service systems and explaining their behaviour [5]. A work system "is a system in which human participants or machines perform work using information, technology, and other resources to produce products and services for internal or external customers" [22]. According to [22] there is no significant difference between the concepts of service system and work system. Hence, the ontology that is being developed for work systems (called Sysperanto [23]) could serve as an ontology of service systems. However, as evidenced in the work system definition, the production of services corresponds to GDL rather than SDL as it implies a 'service as a resource' view.

An interesting development is Ferrario's and Guarino's ontological foundation of Service Science grounded in the DOLCE upper-level ontology [24]. According to [24] "a service is present at a time $t$ and location 1 iff, at time $t$, an agent is explicitly committed to guarantee the execution of some type of action at location 1, on the occurrence of a certain triggering event, in the interest of another agent and upon prior agreement, in a certain way". The basic idea is that there is a commitment state in which one agent guarantees the execution of some type of action in the interest of another agent. This commitment state is the service [25]. In terms of the DOLCE ontology, it is a static event, i.e. an entity which occurs in time. Ferrario and Guarino argue that, because a service is an event and events cannot be owned, a service cannot be transferred [24]. Ferrario and Guarino conclude that "it seems legitimate to assume that goods are objects (endurants, in DOLCE's terms), while services are events (perdurants)" [24]. This conclusion is in line with SDL ('service as a process') and contrasts with the previously discussed works that consider service as a resource.

The proposal by Ferrario and Guarino also extends to service outside the business realm. In [25] they provide examples of public and social services like fire and rescue, snow removal, and child care. They argue, for instance, that here and now there is a commitment state called fire-and-rescue service even if at this very moment there is no fire here and no rescue actions are being performed. In [24] the example of a car repair service is given. The commitment state starts when a mechanic commits with a Public Administration (like a Chamber of Commerce) with a subscription act. Starting from that moment, the mechanic guarantees that he will execute a certain type of job according to the local rules. Although following the line of reasoning of Ferrario and Guarino, the car repair service now exists, there have been no interactions yet with the beneficiaries of the car repair service (i.e. car owners of broken cars). It seems that the understanding of service that is articulated by Ferrario and Guarino is different (broader?) than the understanding posited in this paper. Also because the concept of service system as a configuration of resources [1] is not prominently present in the ontological structure of service proposed by Ferrario and Guarino, the conceptual model of service exchange proposed in this paper was developed starting from REA and Weigand et al.'s proposal, leaving the alignment with the proposed DOLCE foundation for Service Science as a topic for future research. 


\section{The Resource-Service-System Model}

In a first sub-section, the basic conceptual model of service exchange in SDL is presented. A second sub-section extends this basic model with additional model views, capturing different aspects of service systems and their interaction in services.

\subsection{Basic Service Exchange Model}

SDL positions service as a process and not as a type of product as in GDL. The ontological analysis by Ferrario and Guarino [24], [25] supports the SDL view by classifying service as event. Therefore, in an SDL interpretation of REA, service maps closer with economic event than with economic resource. Economic events cause flows of resources. A service is the acting of one or more operant resources on one or more other resources (operand, but possibly also operant [1]). From an economic perspective, the acting of operant resources that embody competences (e.g. the car mechanic) presents a cost (e.g. labour cost). Operand resources that are acted upon may be conveyors of competences and their use (e.g. garage tools and facilities) or consumption (e.g. motor oil, tires) is another cost. The resources that the operant resources are applied to (possibly via conveyor operand resources) are also acted upon and may also present a cost (e.g. a car that is being repaired cannot be used by its owner, the car owner spends time and effort bringing the car to the garage, etc.), but more important is that the integration creates value. A repaired car has more value than a broken car, which is true for both value in use (the SDL perspective) as value in exchange (the GDL perspective) [13].

Based on the similarities between the REA concept of economic event and the meaning of service in SDL, including their respective relations with resources, the conceptual model of service exchange in SDL is constructed starting from the REA conceptual model of economic exchange (Fig. 2) by replacing economic event with service (Fig. 4). Like REA economic resources, resources in SDL are under the control of a particular person. If economic exchanges are service exchanges then the persons controlling resources are service systems (meaning configurations of resources [1]). Therefore, the service system concept is introduced in the model. As shown in Fig. 4, a service system is an aggregate of resources that are controlled by the system. The resource concept is specialized into operant resources and operand resources instead of goods, services and rights. According to [13] the distinction between operant and operand resources can enrich the conceptual foundation of Service Science as service systems are driven by operant resources rather than operand resources. The model shows that at least one operant resource must act in a service and at least one resource must be acted upon, meaning that service implies the application of competences which must be integrated with other resources to create value. These acts_in and be_acted_upon_in relations replace the inflow and outflow relations of REA. 


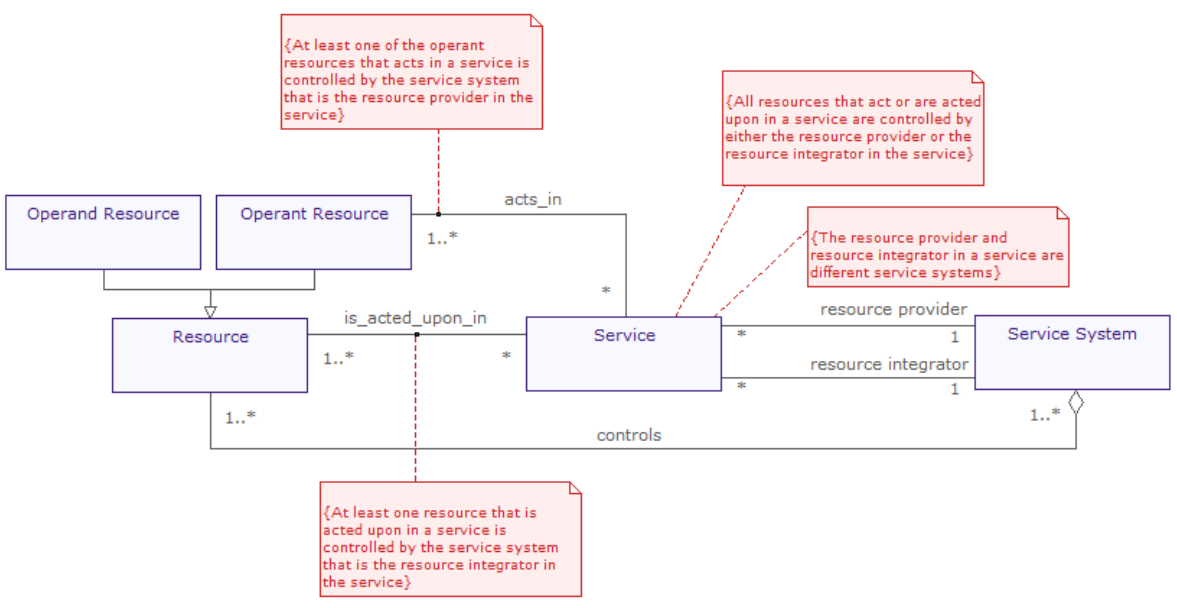

Fig. 4. Basic Resource/Service/System Constellation

The emphasis that REA puts on identifying the persons that are responsible for economic events can be explained by the importance of concepts like governance and control in management (accounting) literature. Enterprises can delegate the responsibility for an economic event to an employee or a subcontractor and this agent can subsequently be held accountable for the event. This emphasis is not found in the SDL literature, so the basic model in Fig. 4 does not include an SDL interpretation of economic agent. Instead, the service systems involved in a service are explicitly identified via value co-creation roles. A resource provider co-creates value with another service system (i.e. a resource integrator) for the benefit of that other system by providing/applying resources. A resource integrator co-creates value with another service system (i.e. a resource provider) for its own benefit by integrating the resources provided/applied by the other system. The term resource provider/integrator is deliberately chosen as in all reviewed service (system) ontologies (see sub-section 2.3), references are made to service provider/client/producer/consumer, which do not make sense as in SDL a service cannot be transferred between parties, be produced by one party, or be consumed by one party.

Finally, the model shown in Fig. 4 also includes a number of constraints, modelled using multiplicity constraints or described textually ${ }^{4}$, which are derived from the SDL definitions of service, service system and service exchange provided in [1].

The car repair or servicing example can be used to illustrate the model shown in Fig. 4, which can be referred to as the Basic Resource/Service/System Constellation. If, for instance, an oil change is the service, then a garage and a car owner participate in the service in the respective roles of resource provider and resource integrator. The car mechanic is an operant resource controlled by the garage that acts upon the car which is an operand resource controlled by the car owner. In the service, other oper-

${ }^{4}$ As the model is articulated using UML, these constraints can also be specified using OCL. For this paper, readability and clarity is more important than precision and formality; therefore a textual description was chosen. 
and resources controlled by the garage (e.g. motor oil, a garage pit, etc.) are acted upon as they convey the oil change competences embodied in the car mechanic that are applied to the car.

The Basic Resource/Service/System Constellation is not a complete conceptual model of service exchange as the reciprocal exchange of services between the service systems is not represented. In other words, the REA duality relation is not represented. Fig. 5 offers a model view that can be integrated with the Basic Resource/Service/System Constellation and that includes a bidirectional is_reciprocal_of relation between services. This Service Exchange View shows via mandatory participation constraints that each service needs a reciprocal service. This means that when a service system provides resources for a service that benefits another service system, then this other service system must provide resources for a requiting service that benefits the first service system. So, in the requiting service the resource provider and resource integrator roles of the service systems that co-create value are switched.

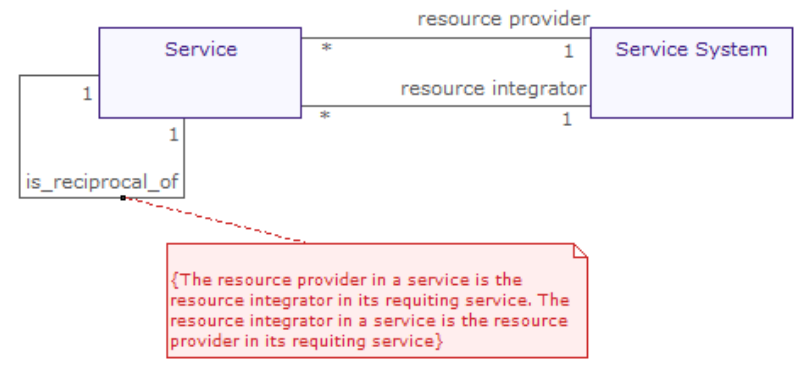

Fig. 5. Service Exchange View

In the car repair example, the garage is a resource provider in the car repair service and a resource integrator in the requiting payment service, whereas the car owner is the resource integrator in the car repair service and the resource provider in the requiting payment service. The car repair service and the payment service are reciprocal, or in REA terms, dual services.

The integration of the Basic Resource/Service/System Constellation (Fig. 4) and the Service Exchange View (Fig. 5) is a conceptual model of service exchange in SDL. This model will be referred to as the Basic Service Exchange Model.

\subsection{Additional Model Views}

The Basic Service Exchange Model does not show that service systems are themselves resources, more particularly operant resources [1]. As service systems are resources, service systems can be composed of other service systems as shown in the Service System Composition View (Fig. 6). As mentioned before (sub-section 2.1), a composition of resources needs to include an operant resource, otherwise it cannot be considered a service system.

Maglio et al. [1] stress that service systems are highly dynamic, meaning that they frequently compose, recompose and decompose over time. The Service System Com- 
position View can be used to keep track of the resources that at any given moment are comprised by a service system. It can for instance be used to identify all the resources (or only those considered relevant for a particular application) that together make up a garage service system. The Basic Service Exchange Model also relates resources to the service systems that control them, but here the idea is more to identify the resources that service systems employ in mutually reciprocal services, for instance to identify the operant and operand resources that a garage provides in an oil change service.

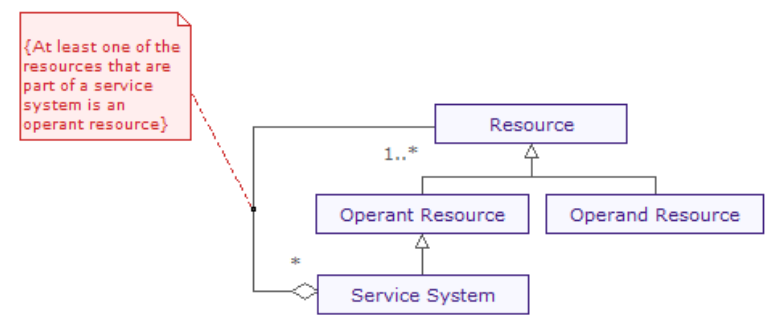

Fig. 6. Service System Composition View

The grounding of the conceptual model of service exchange in REA provides an interesting 'accountability' perspective on service exchanges. The Accountability View in Fig. 7 shows that service systems can delegate their resource providing and integrating responsibilities to agents that can subsequently be held accountable for the service. There is no agent concept in the SDL-based service system definition provided in [1], so the model view that is described here extends the original service system definition.

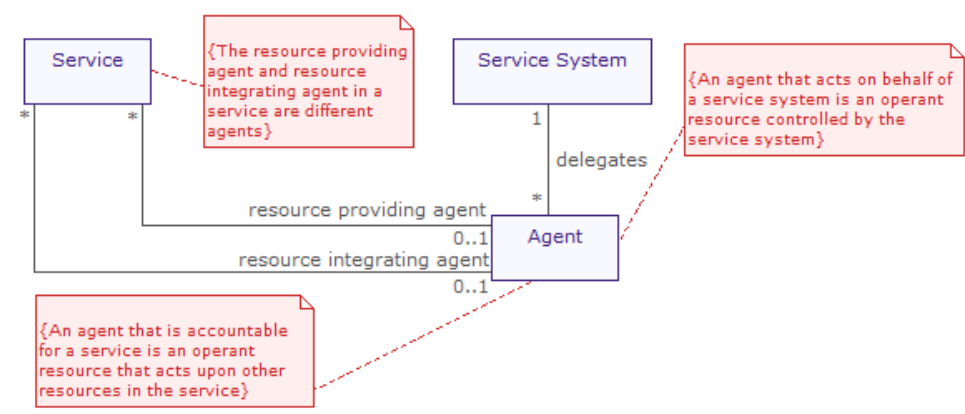

Fig. 7. Accountability View

Regarding the participation of agents in services, two accountability roles can be distinguished. A resource providing agent acts on behalf of the service system that is the resource provider in the service. A resource integrating agent acts on behalf of the service system that is the resource integrator in the service. An agent that acts on behalf of a service system is an operant resource controlled by the system. Furthermore, 
it is an operant resource that acts upon other resources in the service, meaning that specific agent competences are employed in the service. The model view in Fig. 7 further assumes that a service system that is a resource provider or integrator in a service can have at most one agent that is accountable for that service. If accountability is shared amongst a group of persons, then the group is the agent.

By integrating this model view with the Basic Service Exchange Model, the agents acting on behalf of interacting service systems can be explicitly identified. As the model in Fig. 7 shows, this identification of agents is optional. If no agents are identified, then the service system as a whole is held accountable for the service.

In the example of a simple oil change service, the garage will probably delegate the oil change to a car mechanic who has the authority to provide whatever garage's resources necessary for the oil change. If there is no interest in identifying accountability relations, then the Basic Service Exchange Model can be used to represent the car mechanic as an operant resource controlled by the garage and acting upon other resources (including the car controlled by the car owner) in the oil change service. If there is interest in accountability structures, then the Accountability View can be used to indicate that the car mechanic is not just an operant resource controlled by the garage, but that it is acting on behalf of the garage as a resource providing agent. Important to note is that in that case the car mechanic can only be held accountable for the provision of resources and not for their integration which is the responsibility of the resource integrating service system or an agent that acts on behalf of it (e.g. the car owner may fail to bring in his car for servicing).

The last model view that is proposed here is the Service Process View (Fig. 8). The service ontologies reviewed in sub-section 2.3 include notions of service process. In Ferrario's and Guarino's service ontology [24], a service process implements a service. It is stated that the various actions that lead to service production constitute this service process. Also the Basic Service Ontology of Weigand et al. [21] distinguishes services and processes that realize services. Alter provides a model, the Service Value Chain Framework, which details the sequence of service encounters that may occur "before, while, and after a specific service is delivered to a specific customer" [22].

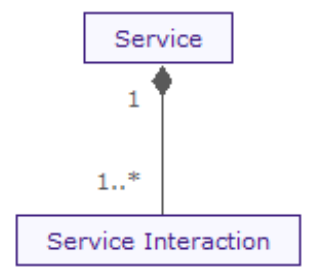

Fig. 8. Service Process View

Service processes that refer to production and delivery of services are hard to reconcile with SDL. An alternative view on the 'dynamics' of a service, which is a process according to SDL, is the ISPAR (Interact - Serve - Propose - Agree - Realize) model proposed by Maglio et al. [1]. This model poses that value co-creation interactions between service systems are service interactions. So a service can be seen as be- 
ing composed of service interactions between the resource providing and integrating service systems (Fig. 8). In each of these service interactions, both service systems are involved. At least one service interaction is required, before we can say that there is a service in which both parties participate.

ISPAR is meant as a normative model that covers all possible interactions between service systems in terms of ten different outcomes, including both 'happy' and 'unhappy' paths. In the 'happy' path, a first service interaction takes place when a service proposal (i.e. a 'value proposition') is communicated. Communication requires a sender and a receiver, so both service systems are involved in the interaction. In the car servicing example, an effective communication of a service proposal has taken place when, for instance, the car owner acknowledges the garage's proposition of conditions and prices for a particular type of car servicing. A second service interaction concerns the reaching of an agreement between both parties on the value proposition. In the context of a service exchange, agreement is reached on the reciprocal services. For instance, the garage agrees to perform a particular type of car servicing on a particular date and time and the car owner agrees to bring in his car on the scheduled date and time, and pay the garage for the car servicing within one month's time. A third interaction is the realization of value by both parties. For the car owner this means that the state of his car is improved and for the garage this means that payment is received. The 'unhappy' path describes negative outcomes or interactions between service systems that do not qualify as service interactions. An example of a negative outcome is when the garage is not paid within the agreed period of time. An example of a non-service interaction is the car mechanic and car owner discussing the current quality and price of motor oil available on the market.

The Service Process view can be integrated with the Basic Service Exchange Model if there is interest in identifying the state in which a certain service is. This state can be expressed in terms of the service interactions that have taken place or that are currently going on.

\section{Discussion and Conclusion}

The Resource-Service-System model proposed in this paper presents a novel perspective on modelling service systems as it differs from its REA conceptual foundation and the REA-based Basic Service Ontology proposed in [21]. Unlike REA and the Basic Service Ontology, the Resource-Service-System model considers service as a process (as in SDL) and not as a resource having intrinsic value (as in GDL). Service exchanges do not transfer services but are constituted of economically reciprocal services, which the model represents as events. Further, service systems are not viewed as value producers or consumers but as value co-creators playing roles of resource provider and integrator.

The model may contribute to Service Science in that it can be used to study various aspects of service systems. The core of the model, i.e. the Basic Resource/Service/System Constellation, can be used to identify all operant and operand resources that the resource providing and integrating service systems contribute in a service, which is interesting from a service management perspective (e.g. for cost ac- 
counting and pricing purposes). Extended with the Service Exchange View, the model explicates the economic motive for service systems to engage in service exchanges, which is useful for service innovation (e.g. designing new value propositions), marketing (e.g. identifying target service beneficiaries), and strategy (e.g. profitability analyses). The Service System Composition View offers additional insight into the resource composition and capabilities of service systems, which is valuable for service operations (e.g. resource acquisition, subcontracting and outsourcing decisions). The Basic Service Exchange Model extended with the Service Process View may provide a detailed account of service interactions between resource provider and integrator, which is interesting from a service engineering perspective (e.g. for measuring and improving service performance as indicated in [1]). Finally, the Accountability View can be used to identify the agents to which service systems delegate resource providing and integrating responsibilities, and which can be held accountable for the realization of the service benefits (i.e. service governance and control).

The Resource-Service-System model is a conceptual model but not an ontology. Further development is needed to make its specification more complete and formal. Also, as ontologies specify shared conceptualizations, the model needs to be evaluated, refined and further elaborated by testing it on actual service exchanges involving a wide variety of service systems. Future research also includes its alignment with ontologies that consider services not only in economic contexts (e.g. the service ontology proposed in [24]). We finally wish to point out that the implicit working hypothesis underlying the development of the model also needs testing, as the usability of the model depends on the usability of SDL as a conceptual foundation of Service Science.

\section{References}

1. Maglio, P.P., Vargo, S.L., Caswell, N., Spohrer, J.: The service system is the basic abstraction of service science. Inf Syst E-Bus Manage 7 395-406 (2009)

2. Maglio, P.P., Srinivasan, S., Kreulen, J.T., Spohrer, J.: Service Systems, Service Scientists, SSME, and Innovation. Communication of the ACM 49, 81-85 (2006)

3. Vargo, S.L., Lusch, R.F.: Evolving to a New Dominant Logic for Marketing. Journal of Marketing 68, 1-17 (2004)

4. Vargo, S.L., Lusch, R.F.: From goods to service(s): Divergences and convergences of logics. Industrial Marketing Management 37, 254-259 (2008)

5. Succeeding through service innovation: A service perspective for education, research, business and government. University of Cambridge Institute for Manufacturing, Cambridge (2008)

6. Chesbrough, H., Spohrer, J.: A Research Manifesto for Services Science. Communications of the ACM 49, 35-40 (2006)

7. Osterwalder, A., Pigneur, Y., Tucci, C.L.: Clarifying Business Models: Origin, Present and Future of the Concept. Communications of the AIS 15, 1-40 (2005)

8. Andersson, B., Bergholtz, M., Edirisuriya, A., Ilayperuma, T., Johannesson, P., Grégoire, B., Schmitt, M., Dubois, E., Abels, S., Hahn, A., Gordijn, J., Weigand, H., Wangler, B.: Towards a Reference Ontology for Business Models. In: Embley, D.W., Olivé, A., Ram, S. (eds.) ER 2006. LNCS, vol. 4215, pp. 482-496. Springer, Heidelberg (2006)

9. Geerts, G.L., McCarthy, W.E.: An Ontological Analysis of the Economic Primitives of the Extended REA Enterprise Information Architecture. International Journal of Accounting Information Systems 3, 1-16 (2002) 
10. Gordijn, J.: Value based requirements engineering: Exploring innovative e-commerce ideas. VU University, Amsterdam (2002)

11. Osterwalder, A.: The Business Model Ontology - a proposition in a design science approach. University of Lausanne, Lausanne (2004)

12. Hruby, P.: Model-Driven Design Using Business Patterns. Springer, New York (2006)

13. Lusch, R.F., Vargo, S.L., Wessels, G.: Toward a conceptual foundation for service science: Contributions from service-dominant logic. IBM Systems Journal 47, 5-14 (2008)

14. Vargo, S.L., Lusch, R.F.: The Four Services Marketing Myths: Remnants from a Manufacturing Model. Journal of Service Research 6, 324-335 (2004)

15. Lusch, R.F., Vargo, S.L.: Service-Dominant Logic: Reactions, Reflections and Refinements. Marketing Theory 6, 281-288 (2006)

16. Spohrer, J., Maglio, P.P., Bailey, J., Gruhl, D.: Steps Toward a Science of Service Systems. IEEE Computer 40, 71-77 (2007)

17. McCarthy, W.E.: The REA Accounting Model: A Generalized Framework for Accounting Systems in a Shared Data Environment. The Accounting Review 57, 554-578 (1982)

18. Geerts, G.L., McCarthy, W.E.: Policy-Level Specifications in REA Enterprise Information Systems. Journal of Information Systems 20, 37-63 (2006)

19. Gailly, F., Laurier, W., Poels, G.: Positioning and Formalizing the REA Enterprise Ontology. Journal of Information Systems 22, 219-248 (2008)

20. Information technology - Business Operational View - Part 4: Business transaction scenarios - Accounting and economic ontology (ISO/IEC 15944-4 ). ISO (2006)

21. Weigand, H., Johannesson, P., Andersson, B., Bergholtz, M.: Value-Based Service Modeling and Design: Toward a Unified View of Services. In: van Eck, P., Gordijn, J., Wieringa, R. (eds.) CAiSE 2009. LNCS, vol. 5565, pp. 410-424. Springer, Heidelberg (2009)

22. Alter, S.: Service system fundamentals: Work system, value chain, and life cycle. IBM Systems Journal 47, 71-85 (2008)

23. Alter, S.: Architecture of Sysperanto: A Model-Based Ontology of the IS Field. Communications of the AIS 15, 1-40 (2005)

24. Ferrario, R., Guarino, N.: Towards an Ontological Foundation for Services Science. In: Domingue, J., Fensel, D., Traverso, P. (eds.) FIS 2008. LNCS, vol. 5468, pp. 152-169. Springer, Heidelberg (2008)

25. Ferrario, R., Guarino, N.: A New Ontological Perspective for Social Service. In: Corradini, F., Polzonetti, A. (eds.) Proceedings of the 2nd International Conference on Methodologies, Technologies and Tools Enabling e-Government, pp. 41-51. Halley (2008) 